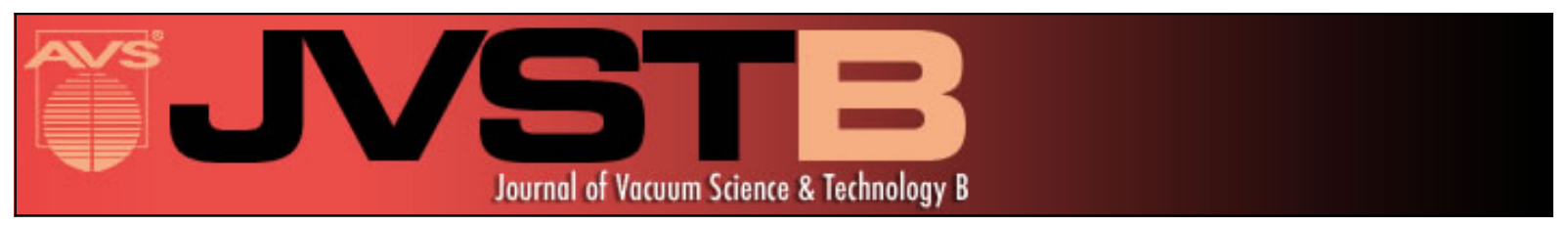

\title{
Molecular beam epitaxy using bismuth as a constituent in InAs and a surfactant in InAs/InAsSb superlattices
}

Preston T. Webster, Nathaniel A. Riordan, Chaturvedi Gogineni, Shi Liu, Jing Lu, Xin-Hao Zhao, David J. Smith, Yong-Hang Zhang, and Shane R. Johnson

Citation: Journal of Vacuum Science \& Technology B 32, 02C120 (2014); doi: 10.1116/1.4868111

View online: http://dx.doi.org/10.1116/1.4868111

View Table of Contents: http://scitation.aip.org/content/avs/journal/jvstb/32/2?ver=pdfcov

Published by the AVS: Science \& Technology of Materials, Interfaces, and Processing

\section{Articles you may be interested in}

Investigation of high hole mobility In $0.41 \mathrm{Ga} 0.59 \mathrm{Sb} / \mathrm{Al} 0.91 \mathrm{Ga0} .09 \mathrm{Sb}$ quantum well structures grown by molecular beam epitaxy

Appl. Phys. Lett. 104, 052111 (2014); 10.1063/1.4865091

Impact of substrate temperature on the structural and optical properties of strain-balanced InAs/InAsSb type-II superlattices grown by molecular beam epitaxy

Appl. Phys. Lett. 102, 071903 (2013); 10.1063/1.4793231

Structural properties of InAs/InAs1-xSbx type-II superlattices grown by molecular beam epitaxy

J. Vac. Sci. Technol. B 30, 02B106 (2012); 10.1116/1.3672026

$\mathrm{Sb}$ surfactant effect on GalnAs/GaAs highly strained quantum well lasers emitting at $1200 \mathrm{~nm}$ range grown by molecular beam epitaxy

J. Appl. Phys. 96, 44 (2004); 10.1063/1.1760841

Al 1-x In x As 1-y Sb y / GaSb heterojunctions and multilayers grown by molecular beam epitaxy for effectivemass superlattices

J. Vac. Sci. Technol. B 16, 1385 (1998); 10.1116/1.590080

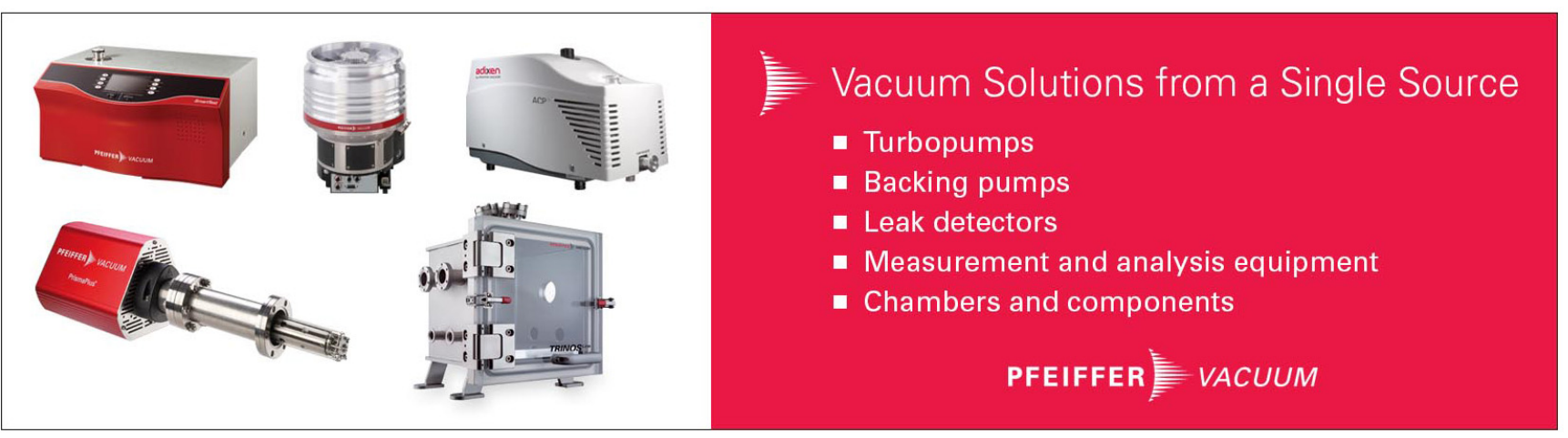




\title{
Molecular beam epitaxy using bismuth as a constituent in InAs and a surfactant in InAs/InAsSb superlattices
}

\author{
Preston T. Webster, Nathaniel A. Riordan, Chaturvedi Gogineni, and Shi Liu \\ Center for Photonics Innovation and School of Electrical, Computer, and Energy Engineering, \\ Arizona State University, Tempe, Arizona 85287 \\ Jing Lu and Xin-Hao Zhao \\ Center for Photonics Innovation and School for Engineering of Matter, Transport, and Energy, \\ Arizona State University, Tempe, Arizona 85287 \\ David J. Smith \\ Center for Photonics Innovation and Department of Physics, Arizona State University, Tempe, Arizona 85287 \\ Yong-Hang Zhang and Shane R. Johnson ${ }^{\text {a) }}$ \\ Center for Photonics Innovation and School of Electrical, Computer, and Energy Engineering, \\ Arizona State University, Tempe, Arizona 85287
}

(Received 6 January 2014; accepted 26 February 2014; published 13 March 2014)

\begin{abstract}
Alloying bismuth with InAs provides a ternary material system near the $6.1 \AA$ lattice constant, which covers the technologically important mid- and long-wavelength infrared region. One challenge for this material system is that it is not straightforward to incorporate bismuth into the bulk InAs lattice, since bismuth has a tendency to surface-segregate and form droplets during growth. In this work, the conditions for InAsBi growth using molecular beam epitaxy are explored.

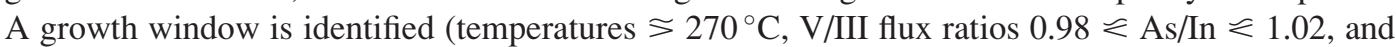
$\mathrm{Bi} / \mathrm{In} \cong 0.065)$ for droplet-free, high-quality crystalline material, where InAsBi layers with compositions of up to $5.8 \%$ bismuth (nearly lattice-matched to $\mathrm{GaSb}$ ) are attained. The structural quality of InAsBi bulk and quantum well samples is evaluated using x-ray diffraction and transmission electron microscopy. The optical quality is assessed using photoluminescence, which is observed from quantum well structures up to room temperature and from thick, low Bi-content bulk layers at low temperatures. Bismuth is also used as a surfactant during the growth of InAs/InAsSb superlattices at $430^{\circ} \mathrm{C}$ where it is observed that a small bismuth flux changes the surface reconstruction of InAs from $(2 \times 1)$ to $(1 \times 3)$, reduces the sticking coefficient of antimony, results in a slight increase in photoluminescence intensity, does not significantly incorporate, and does not alter the surface morphology. (C) 2014 American Vacuum Society.
\end{abstract}

[http://dx.doi.org/10.1116/1.4868111]

\section{INTRODUCTION}

Alloying semiconductor materials provides additional degrees of freedom to engineer the bandgap energy and band offsets for electronic and optoelectronic device applications. Specifically, alloying host materials with heavier elements typically reduces the bandgap energy. For instance, when Bi is alloyed with GaAs or InAs, the bandgap reduction comes primarily from the upward shift of the heavy and light hole bands, while the split-off hole band and conduction band are only weakly affected. ${ }^{1}$ The bandgap reduction associated with Bi-alloying is significantly larger than for In (12 $\mathrm{meV} / \%)^{2}$ or $\mathrm{Sb}(17 \mathrm{meV} / \%)^{2}$ alloying in $\mathrm{GaAs}$ or $\mathrm{Sb}(7.2$ $\mathrm{meV} / \%)^{2}$ alloying in InAs. Large bandgap reduction rates that vary with mole fraction are reported for $\mathrm{GaAs}_{1-\mathrm{x}} \mathrm{Bi}_{\mathrm{x}}$ with $90 \mathrm{meV}$ per $\% \mathrm{Bi}$ at $\mathrm{x}=0.01,57 \mathrm{meV}$ per $\% \mathrm{Bi}$ at $\mathrm{x}=$ 0.05 , and $43 \mathrm{meV}$ per $\% \mathrm{Bi}$ at $\mathrm{x}=0.10 ;{ }^{3} 83 \mathrm{meV} / \% \mathrm{Bi}$ for $\mathrm{x}$ $=0-0.036 ;{ }^{4}$ and $62 \mathrm{meV} / \% \mathrm{Bi}$ for $\mathrm{x}=0.02-0.08 .{ }^{5}$ Since the strain introduced by incorporation of $\mathrm{Bi}$ is not correspondingly larger, a greater bandgap reduction is achieved with less strain using Bi compared to In or Sb.

a)Electronic mail: shane.johnson@asu.edu
A bound state will split off from the host band structure when the on-site energy of an isoelectronic impurity atom, such as $\mathrm{Bi}$, is sufficiently different from the energy of the host orbitals. Otherwise, the impurity atom, which has similar electronic properties as the host, simply distorts the host band structure. Although the potential of one $\mathrm{Bi}$ atom may not be enough to pull a localized state out of the band continuum, two next-nearest neighbor $\mathrm{Bi}$ atoms or larger $\mathrm{Bi}$ clusters may be sufficient. This phenomenon introduces a distribution of localized states in the vicinity of the valence band. ${ }^{6,7}$ This behavior is a unique feature in the electronic band structure of III-V-Bi semiconductors.

The smallest reported room temperature bandgap of bulk $\mathrm{InAs}_{1-\mathrm{x}} \mathrm{Sb}_{\mathrm{x}}$ is $100 \mathrm{meV},{ }^{8}$ which occurs at a composition of $\mathrm{x}$ $=0.65$ and is not lattice-matched to any conventional substrate. For small bandgap materials near the lattice constant of GaSb, InAs can be alloyed with modest amounts of Bi. The band anticrossing model accurately predicts the bandgap of GaAsSb (Ref. 9) and reasonably predicts the bandgap of GaAsBi (Ref. 9) for Bi mole fractions up to $4 \%$. When applied to InAsBi, this model predicts a bandgap reduction of $58 \mathrm{meV} / \% \mathrm{Bi}$, which is consistent with the reported value of $55 \mathrm{meV} / \% \mathrm{Bi}$ in samples grown by metalorganic vapor 


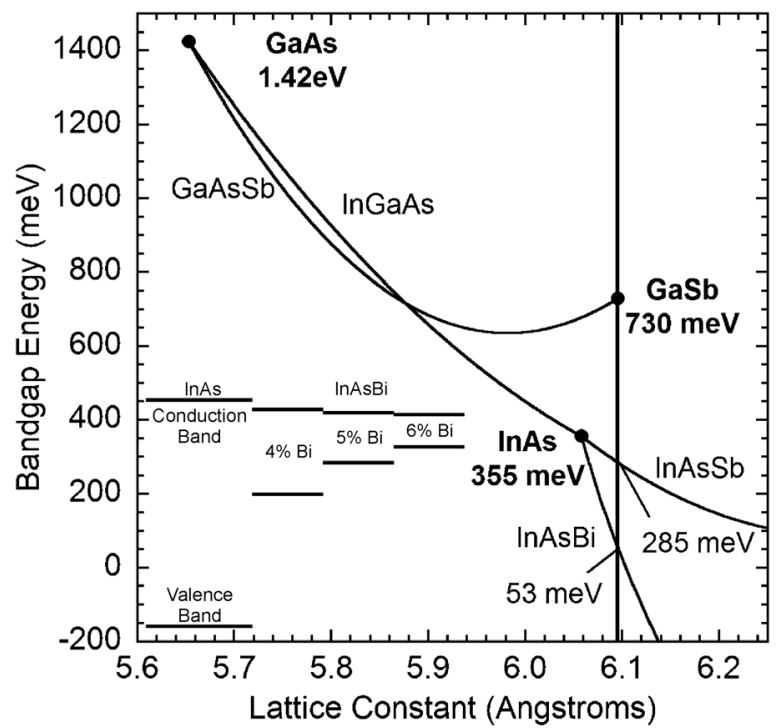

FIG. 1. Room temperature bandgap energy vs lattice constant of selected III$\mathrm{V}$ ternaries. The bandgap of InAsBi decreases by $58 \mathrm{meV}$ per percent $\mathrm{Bi}$ and has a type-I band alignment to InAs (see inset). $\operatorname{InAs}_{0.94} \mathrm{Bi}_{0.06}$ is lattice-matched to $\mathrm{GaSb}$ and becomes semimetallic at $7.3 \% \mathrm{Bi}$.

phase epitaxy. ${ }^{10}$ The room temperature bandgaps of InAsBi and InAsSb are compared in Fig. 1; the inset shows the band offsets of InAs and InAsBi with 4, 5, and 6\% Bi. The bandgap of InAsBi lattice-matched to $\mathrm{GaSb}$ is $53 \mathrm{meV}$ at $6.0 \% \mathrm{Bi}$ and becomes semimetallic at $7.3 \% \mathrm{Bi}$. Furthermore, its type-I band alignment provides strong wavefunction overlap between electrons and holes in InAs/InAsBi heterostructures, making them strong absorbers and good candidates for high performance far-infrared optoelectronic materials.

Surfactant species are widely used during molecular beam epitaxy growth due to their beneficial effects on surface morphology and material quality. In particular, the use of reactive ${ }^{11}$ surfactants, such as $\mathrm{Te}$, have been reported to delay relaxation in highly strained InAs (Ref. 12) or InGaAs; ${ }^{13}$ while the use of nonreactive ${ }^{11}$ surfactants have been reported to increase photoluminescence (PL) intensity and carrier mobility while decreasing surface roughness in $\mathrm{n}$-AlGaAs using $\mathrm{Sb},{ }^{14,15}$ and improving N-incorporation, photoluminescence intensity, and surface morphology in GaAsN using Bi. ${ }^{16,17}$ Both $\mathrm{Sb}$ and $\mathrm{Bi}$ are suitable surfactants for arsenides as the typical growth temperatures are sufficiently high that little $\mathrm{Sb}$ or $\mathrm{Bi}$ incorporates, and the trace amounts that do are isoelectronic with As. Likewise, $\mathrm{Bi}$ is a suitable surfactant for antimonides such as InAs/InAsSb superlattices.

This work presents a detailed investigation of the molecular beam epitaxy growth and the structural and optical properties of InAsBi alloys on GaSb substrates, and the effects of $\mathrm{Bi}$ as a surfactant during the growth of InAs/InAsSb superlattices on $\mathrm{GaSb}$ substrates.

\section{GROWTH OF InAsBi}

Bismuth is a difficult element to incorporate into III-V alloys during molecular beam epitaxy growth because it surface segregates and evaporates from the surface at the typical
III-V growth temperatures of $400-700{ }^{\circ} \mathrm{C}$, and it forms surface droplets when the growth temperature is reduced below $400{ }^{\circ} \mathrm{C}$. Significant Bi incorporation occurs when nearstoichiometric group- $\mathrm{V}$ fluxes and low growth temperatures $\left(\sim 300^{\circ} \mathrm{C}\right)$ are utilized. In this work, Bi is alloyed with As on the group-V sublattice; growth conditions (flux ratios and temperatures) are identified at which the growth of highquality droplet-free InAsBi occurs, and a mechanism is proposed for $\mathrm{Bi}$ incorporation based on the amount of As present on the surface.

The radial profile of the As/In flux ratio shown in Fig. 2 is measured/calibrated during the growth of InAs at $300{ }^{\circ} \mathrm{C}$ on a $50 \mathrm{~mm}$ InAs wafer under rotation. The As/In flux ratio at the center of the wafer is calibrated using reflection highenergy electron diffraction (RHEED). Starting with an Asoverpressure, the As-flux is progressively reduced until the surface reconstruction transforms from an As-rich $(2 \times 4)$, to a $(1 \times 1)$, to an In-rich $(4 \times 2)$; the transitional $(1 \times 1)$ surface reconstruction indicates that the As/In flux is unity. The radial profile is determined under growth, starting with unity As/In flux at the wafer center and incrementally reducing the As-flux in 1\% steps. As the As-flux is reduced, distinct concentric rings of haze develop due to the formation of Indroplets on the In-rich growth surfaces. The As/In flux ratio in the center region of the wafer is relatively constant, but increases by approximately $4 \%$ from a radius of $10 \mathrm{~mm}$ to the edge of a $50 \mathrm{~mm}$ wafer. The nonuniformity of the As/In flux ratio is mainly due to a $\sim 3 \%$ decrease in the In-flux moving radially from the center to the edge of the wafer.

This small nonuniformity is not that important for the growth of many materials that are grown with As/III ratios greater than unity, but $4 \%$ is very significant when the fluxes are near-stoichiometric, as is the case for the growth of III$\mathrm{V}$-Bi materials. In the following experiments, InAsBi is grown with a target As/In flux ratio at the center of each wafer keeping in mind the change of the As/In flux ratio across the wafer. By keeping track of the As/In flux ratio and characterizing the InAsBi radially across the wafer, multiple designs (different As/In fluxes) are studied on a single 50 mm wafer.

The samples are grown on $1 / 450 \mathrm{~mm}$ or whole $50 \mathrm{~mm}$ $\mathrm{Zn}$-doped GaSb substrates in a VG-V80H solid source molecular beam epitaxy system at temperatures from 260 to $300{ }^{\circ} \mathrm{C}$, calibrated using an Ircon Modline 3 (model 3G$10 \mathrm{C} 05$ ) infrared pyrometer. For the particular As/In flux profile shown in Fig. 2, samples grown on 1/4 wafers have a relatively uniform As/In flux ratio (within 1\%), whereas samples grown on full $50 \mathrm{~mm}$ wafers have a $4 \%$ greater As/In flux ratio at the edge of the wafer than in the center.

The InAsBi bulk and quantum well sample cross-sections are shown in Fig. 3. The bulk samples consist of a $500 \mathrm{~nm}$ thick GaSb buffer, a $15 \mathrm{~nm}$ thick InAs spacer, and a $1 \mu \mathrm{m}$ thick InAsBi layer; the entire structure is capped with a $10 \mathrm{~nm}$ thick InAs layer (samples A-E), a $10 \mathrm{~nm}$ thick GaSb layer (sample H), or left uncapped (samples F and G). The quantum well samples consist of a $500 \mathrm{~nm}$ thick GaSb buffer, a $10 \mathrm{~nm}$ thick AlSb barrier, a $50 \mathrm{~nm}$ thick InAs confinement layer, a $10 \mathrm{~nm}$ thick InAsBi quantum well, a $50 \mathrm{~nm}$ thick 


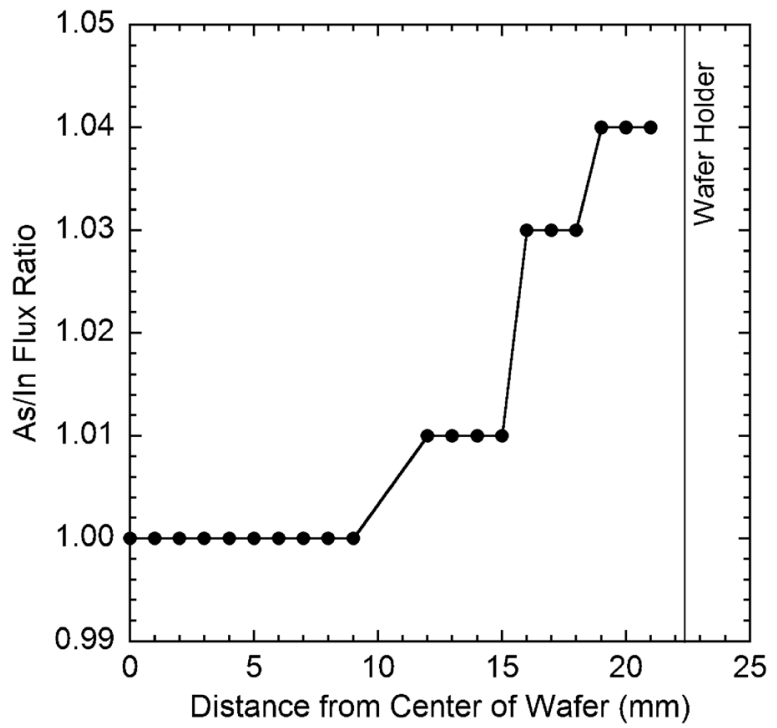

FIG. 2. Radial profile of the As/In flux ratio (under rotation) measured during the growth of InAs on InAs at $300{ }^{\circ} \mathrm{C}$ on a $50 \mathrm{~mm}$ wafer. The unity flux ratio is given at the wafer center by the $(1 \times 1)$ surface reconstruction (measured by reflection high-energy electron diffraction) and the radial profile is determined by further reducing the As-flux in $1 \%$ increments, which results in the formation of concentric haze rings across the wafer as In-droplets form in regions deficient in As.

InAs confinement layer, a $10 \mathrm{~nm}$ thick AlSb barrier, and a $10 \mathrm{~nm}$ thick GaSb cap. The AlSb/InAs/InAsBi/InAs/AlSb structure provides confinement for photogenerated carriers. The growth conditions and $\mathrm{Bi}$ mole fractions are summarized in Table I for the bulk material and in Table II for the quantum wells.

All growths are done at a constant In-flux of $2.73 \times 10^{14}$ atoms $\mathrm{cm}^{-2} \mathrm{~s}^{-1}$ that corresponds to an InAs on InAs growth rate of about one half monolayer per second. This flux corresponds to growth rates of $9.10 \mathrm{~nm}$ per minute for InAs on InAs, $9.15 \mathrm{~nm}$ per minute for InAs on $\mathrm{GaSb}$, and $9.27 \mathrm{~nm}$ per minute for InAsBi lattice-matched to GaSb. The $9.15 \mathrm{~nm}$ per minute growth rate and the inferred In-flux is accurately calibrated by x-ray diffraction (XRD) measurements of the period thickness of strain-balanced InAs/InAsSb superlattices grown on GaSb. The InAsBi layers grown between 280 and $260^{\circ} \mathrm{C}$ with $\mathrm{V} / \mathrm{In}$ flux ratios greater than unity and $\mathrm{Bi} / \mathrm{In}$ flux ratios $\sim 0.065$ exhibited group- $\mathrm{V}$ terminated surface reconstructions: $(2 \times 3)$ for droplet-free growth and $(2 \times 1)$ for

\begin{tabular}{|c|}
\multicolumn{1}{c|}{ Bulk Structure } \\
\hline $10 \mathrm{~nm}$ InAs \\
\hline $1000 \mathrm{~nm}$ InAsBi \\
\hline $15 \mathrm{~nm}$ InAs \\
\hline \hline $500 \mathrm{~nm}$ GaSb Buffer \\
\hline \hline $\begin{array}{c}\text { p-type GaSb } \\
\text { Substrate }\end{array}$ \\
\hline
\end{tabular}

(a)

Quantum Well
\begin{tabular}{|c|}
\hline $10 \mathrm{~nm} \mathrm{GaSb}$ \\
\hline $10 \mathrm{~nm}$ AISb \\
\hline $50 \mathrm{~nm}$ InAs \\
\hline $10 \mathrm{~nm}$ InAsBi \\
\hline $50 \mathrm{~nm}$ InAs \\
\hline $10 \mathrm{~nm} \mathrm{AISb}$ \\
\hline $500 \mathrm{~nm} \mathrm{GaSb}$ \\
\hline $\begin{array}{c}\text { p-type GaSb } \\
\text { Substrate }\end{array}$ \\
\hline
\end{tabular}

(b)

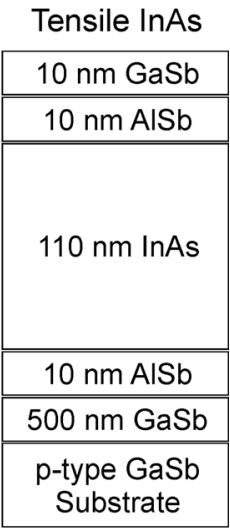

(c)

FIG. 3. Cross-section schematics of InAsBi bulk samples (a), quantum well samples (b), and tensilely strained InAs reference sample (c).

growth with Bi-droplet formation that evolves to a spotty $2 \times$ with chevrons as droplets begin to cover the surface. The InAsBi quantum well layers grown at $300^{\circ} \mathrm{C}$ with near unity $\mathrm{V} / \mathrm{In}$ flux ratios exhibited an In-terminated $(4 \times 2)$ surface reconstruction.

The surface and structural quality of $1 \mu \mathrm{m}$ thick bulk InAsBi samples is found to be strongly dependent on the group-V fluxes. Each sample developed concentric rings of rough and smooth growth. Photos of samples A, B, and E are shown in Fig. 4, where the rough regions are identified as droplets using Nomarski interference contrast and scanning electron microscope images. Energy-dispersive x-ray spectroscopy verifies that the droplets are composed of $\mathrm{Bi}$, a result that is consistent with $\omega-2 \theta$ XRD measurements of the Bi mole fraction which show that the droplet-free regions have significantly larger Bi-content than the droplet-covered regions. The plot in Fig. 4 shows the 004-plane XRD from the smooth surface regions of the six bulk samples A, B, D, $\mathrm{E}, \mathrm{F}$, and $\mathrm{G}$. The Bi-composition is calculated using Vegard's law and the $6.686 \AA$ theoretical lattice constant of InBi. ${ }^{1} \mathrm{Bi}$ mole fractions up to the nearly lattice-matched composition of $5.8 \% \mathrm{Bi}$ are attained.

Transmission electron micrographs from the smooth areas of sample A (with $5.8 \% \mathrm{Bi}$ ) are shown in Fig. 5 where the regions imaged are shown on the cross-section schematic. The upper micrograph (a) is a high-resolution image that confirms excellent crystallinity at the top of the InAsBi layer

TABLE I. Growth conditions and Bi composition measured by X-ray diffraction for $1 \mu \mathrm{m}$ thick InAsBi samples grown on $1 / 4$ or full $50 \mathrm{~mm}$ GaSb substrates.

\begin{tabular}{|c|c|c|c|c|c|c|c|}
\hline Sample & $\begin{array}{l}\text { Run } \\
\text { No. }\end{array}$ & $\begin{array}{c}\text { Substrate } \\
(1 / 4 \text { or full } 50 \mathrm{~mm})\end{array}$ & $\begin{array}{c}\text { Growth } \\
\text { temperature }\left({ }^{\circ} \mathrm{C}\right)\end{array}$ & $\begin{array}{l}\mathrm{Bi} / \mathrm{In} \\
\text { flux ratio }\end{array}$ & $\begin{array}{l}\mathrm{As} / \mathrm{In} \text { flux } \\
\text { ratio (center) }\end{array}$ & $\begin{array}{l}\text { Maximum } \\
\text { Bi mole fraction }\end{array}$ & $\begin{array}{c}\text { As/In flux ratio } \\
\text { (at point of x-ray diffraction measurement) }\end{array}$ \\
\hline A & B1975 & Full & 280 & 0.065 & 0.96 & 0.058 & $0.98-0.99$ \\
\hline B & B1976 & Full & 270 & 0.065 & 0.96 & 0.055 & $0.99-1.00$ \\
\hline $\mathrm{C}$ & B1982 & Full & 260 & 0.065 & 1.00 & 0.054 & $1.03-1.04$ \\
\hline D & B1979 & Full & 270 & 0.065 & 1.00 & 0.052 & $1.00-1.02$ \\
\hline E & B1974 & full & 280 & 0.060 & 1.00 & 0.049 & $1.00-1.03$ \\
\hline $\mathrm{F}$ & B1973 & $1 / 4$ & 280 & 0.060 & 1.00 & 0.047 & 1.00 \\
\hline G & B1972 & $1 / 4$ & 280 & 0.060 & 1.05 & 0.045 & 1.05 \\
\hline $\mathrm{H}$ & B1967 & $1 / 4$ & 300 & 0.100 & 1.50 & 0.0022 & 1.50 \\
\hline
\end{tabular}


TABLE II. Growth conditions and Bi composition for $10 \mathrm{~nm}$ InAsBi quantum wells (samples 1 and 2) and tensilely strained InAs (sample 3 ) grown at $300^{\circ} \mathrm{C}$ on $50 \mathrm{~mm} \mathrm{GaSb}$ substrates.

\begin{tabular}{|c|c|c|c|c|c|c|c|}
\hline Sample & $\begin{array}{l}\text { Run } \\
\text { No. }\end{array}$ & $\begin{array}{c}\text { Substrate } \\
(1 / 4 \text { or full } 50 \mathrm{~mm})\end{array}$ & $\begin{array}{c}\text { Growth } \\
\text { temperature }\left({ }^{\circ} \mathrm{C}\right)\end{array}$ & $\mathrm{Bi} / \mathrm{In}$ flux ratio & $\begin{array}{c}\mathrm{As} / \mathrm{In} \\
\text { flux ratio (center) }\end{array}$ & $\begin{array}{c}\text { Bi mole } \\
\text { fraction (peak) }\end{array}$ & $\begin{array}{l}\mathrm{As} / \mathrm{In} \text { flux ratio } \\
\text { (at point of peak incorporation) }\end{array}$ \\
\hline 1 & B1990 & Full & 300 & 0.021 & 1.00 & 0.0029 & 1.01 \\
\hline 2 & B1987 & Full & 300 & 0.021 & 0.97 & 0.0029 & 1.01 \\
\hline 3 & B1991 & Full & 300 & - & 1.30 & - & - \\
\hline
\end{tabular}

and InAs cap. The lower micrograph (b) is a bright-field image which shows that this sample has no visible defects over large lateral distances. These results indicate excellent crystal quality with few defects over many hundreds of nanometers.

The growth space for high-quality InAsBi is mapped in Fig. 6 by plotting growth temperature versus the V/In flux ratio for the five bulk samples A, B, C, D, and E grown on full $50 \mathrm{~mm}$ wafers (see Table I). The radial location of InAsBi growth with and without droplet formation is determined across each of the $50 \mathrm{~mm}$ wafers, and the corresponding As/In flux ratios are established at each location using the As/In flux ratio profile given in Fig. 2 scaled by the As/In flux ratio setting at the center of each wafer. The growth space sampled by each wafer is shown by the thick horizontal line of each rectangular area labeled by sample name. The ovals drawn along each sample region indicate the location and the percentage Bi mole fraction measured by XRD. Three distinct regions of growth are identified in the plot, droplet-free high-quality crystalline growth (not shaded), $<1 \mu \mathrm{m}$ diameter Bi-droplets with $1 \times 10^{7} \mathrm{~cm}^{-2}$ density

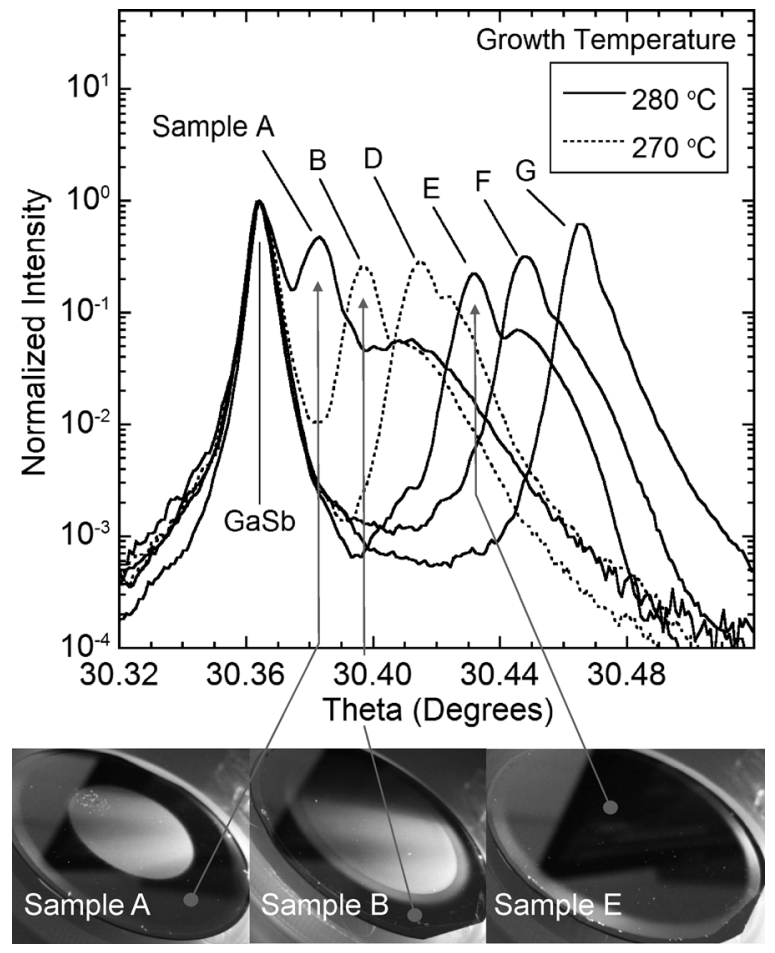

FIG. 4. Plot shows x-ray diffraction from the 004-planes of $1 \mu \mathrm{m}$ thick InAsBi layers grown on GaSb. For three of the samples, the position of the measurement is shown by the solid lines to the photos below. (shaded with vertical lines), and $3 \mu \mathrm{m}$ diameter Bi-droplets with $5 \times 10^{6} \mathrm{~cm}^{-2}$ density (shaded with diagonal lines).

Samples $\mathrm{A}$ and $\mathrm{E}$ are grown at $280^{\circ} \mathrm{C}$ with different group-V fluxes. Sample A is grown with a $\mathrm{Bi} / \mathrm{In}$ flux ratio of 0.065 and an As/In flux ratio of 0.96 at the wafer center increasing to 1.00 at the edge. This sample is very rough at the center of the wafer, having formed a dense array of 1-3 $\mu \mathrm{m}$ diameter droplets (see left-hand photo in Fig. 4), and abruptly becomes smooth near the point at which the As/In flux ratio is 0.97 . The $\mathrm{Bi}$ composition in the smooth region of the sample is $5.8 \%$, measured by XRD. Sample E is grown with a $\mathrm{Bi} / \mathrm{In}$ flux ratio of 0.060 and an $\mathrm{As} / \mathrm{In}$ flux ratio of 1.00 at the wafer center increasing to 1.04 at the edge. This sample is smooth in the wafer center, with the formation of submicron sized Bi-droplets at the wafer edge. Samples B and D are grown at $270{ }^{\circ} \mathrm{C}$ with a $\mathrm{Bi} / \mathrm{In}$ flux ratio of 0.065 and an As/In flux ratio of 0.96-1.00 (center to edge) for sample B and 1.00-1.04 (center to edge) for sample D, resulting in a continuous range of growth conditions at $270{ }^{\circ} \mathrm{C}$. Sample $\mathrm{C}$ is grown at $260^{\circ} \mathrm{C}$ with a $\mathrm{Bi} / \mathrm{In}$ flux ratio of 0.065 and an As/In flux ratio of 1.00-1.04 (center to edge). Under these growth conditions, Bi-droplets are formed across the entire growth surface, though the droplets

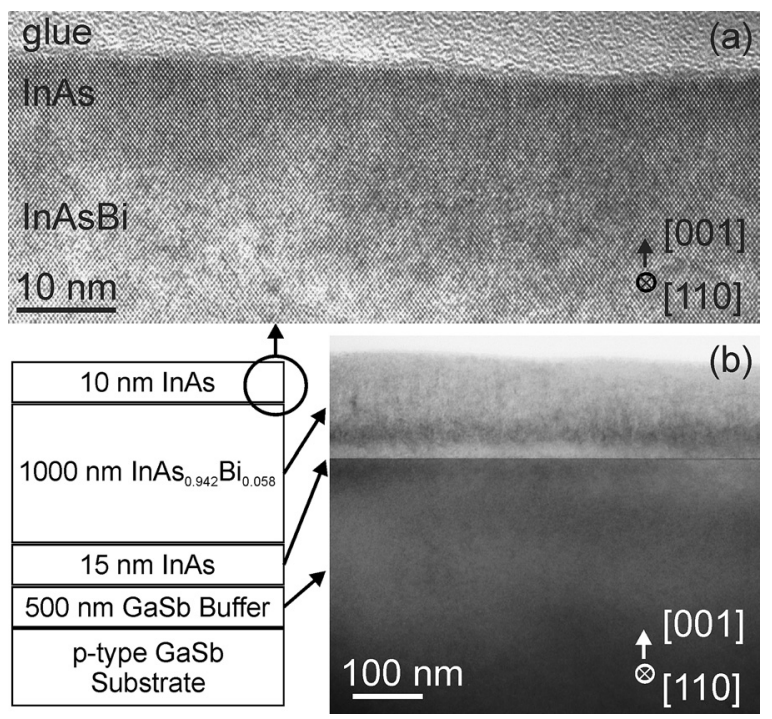

FIG. 5. Cross-section electron micrographs showing nearly lattice-matched bulk InAs $\mathrm{As}_{0.942} \mathrm{Bi}_{0.058}$; high-resolution (a) and bright-field (b); sample regions imaged are shown on the cross-section schematic. The high-resolution image shows excellent crystallinity at the top of the InAsBi layer and InAs cap, and the bright-field image shows that the material has no visible defects over large lateral distances. 


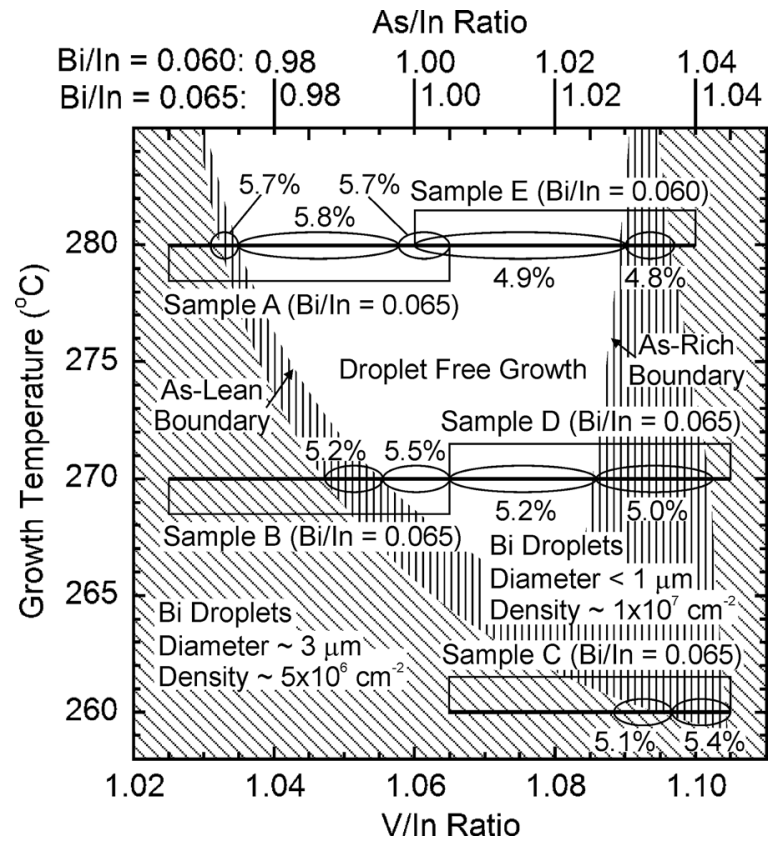

FIG. 6. Growth temperature vs the V/In (As/In + Bi/In) flux ratio (lower horizontal axis) during the growth of InAsBi. The As/In flux ratio is shown on the upper horizontal axis for sample $\mathrm{E}$ (top scale) with a $\mathrm{Bi} / \mathrm{In}$ flux ratio of 0.060 and for the other samples (bottom scale) with a $\mathrm{Bi} / \mathrm{In}$ flux ratio of 0.065. Three distinct growth regions are shown: droplet-free (not shaded), submicron diameter Bi droplets with density of $\sim 1 \times 10^{7} \mathrm{~cm}^{-2}$ (vertical lines), and $\sim 3 \mu \mathrm{m}$ diameter Bi droplets with density of $\sim 5 \times 10^{6} \mathrm{~cm}^{-2}$ (diagonal lines). The growth space sampled by each growth is shown by the thick horizontal line of each rectangular area labeled by sample name. The ovals drawn along each sample region indicate the location and $\mathrm{Bi}$ mole fraction measured by x-ray diffraction.

within $4 \mathrm{~mm}$ of the edge are much smaller than those in the center.

The growths on $1 / 450 \mathrm{~mm} \mathrm{GaSb}$ wafers (samples F, G, and $\mathrm{H}$ ) are not shown in Fig. 6, and due to their smaller size the As/In flux is uniform to within $1 \%$ across the samples. Sample $\mathrm{F}$ is grown under the same conditions as the center of the larger sample, sample $\mathrm{E}\left(280^{\circ} \mathrm{C}, 1.00 \mathrm{As} / \mathrm{In}\right.$ flux ratio, and $0.060 \mathrm{Bi} / \mathrm{In}$ flux ratio) and it has a slightly smaller $\mathrm{Bi}$ mole fraction $(4.7 \%$ compared to $4.9 \%)$. Sample $\mathrm{G}$ has a slightly lower Bi mole fraction (4.5\%) compared to samples E (4.9-4.8\%) and F (4.7\%) grown at the same temperature and Bi-flux, which is consistent with the presence of a larger As/In flux ratio. However, the observed Bi deficiency did not result in as many $\mathrm{Bi}$ droplets as would be expected from the results presented in Fig. 6. Sample $\mathrm{H}$ is grown at $300^{\circ} \mathrm{C}$ with a $1.50 \mathrm{As} / \mathrm{In}$ flux ratio and a $0.10 \mathrm{Bi} / \mathrm{In}$ flux ratio. Under these nonstoichiometric As/In growth conditions, only a small percentage of the $\mathrm{Bi}$ incorporates with most of the $\mathrm{Bi}$ remaining on the surface to form a dense $\sim 4 \times 10^{7} \mathrm{~cm}^{-2}$ coverage of $1 \mu \mathrm{m}$ diameter droplets. This is approximately four times more surface Bi than observed in the droplet covered regions of samples A through E presented in Fig. 6, which were grown with near-stoichiometric As/In flux ratios and lower Bi fluxes. This growth (sample $\mathrm{H}$ ) resulted in a thick, 90\% relaxed, InAsBi layer containing $0.22 \% \mathrm{Bi}$; the relaxation and composition are determined self consistently from the perpendicular strain of the InAsBi lattice measured by 004-plane XRD and the shift in the photoluminescence peak predicted by strain and the band anticrossing model.

The above results indicate that $\mathrm{Bi}$ incorporation is very sensitive to the As/In flux ratio, and that droplet-free growth occurs near As/In stoichiometry. Furthermore, the incorporation of $\mathrm{Bi}$ in the droplet-free growth window peaks when the As-flux is slightly lean $(\mathrm{As} / \mathrm{In}<1.00)$; is reduced by $0.1-0.3 \%$ for As/In flux ratios between 1.00 and 1.02 ; and is further reduced for As/In flux ratios greater than 1.02, indicating that As is a significantly stronger competitor than $\mathrm{Bi}$ for group- $\mathrm{V}$ lattice sites. Moreover, the formation of $\mathrm{Bi}$ droplets on the surface indicates that at least some of the $\mathrm{Bi}$ that is not incorporated stays on the surface and coalesces into droplets. Nevertheless, there is a region with reduced $\mathrm{Bi}$ incorporation (1.00-1.02 As/In flux ratio) where the surface remains droplet-free. In this As rich $(\mathrm{As} / \mathrm{In}>1.00)$ growth region not all of the $\mathrm{Bi}$ or $\mathrm{As}$ incorporates, resulting in an excess of approximately $1 \% \mathrm{Bi} / \mathrm{In}$ and $6 \% \mathrm{As} / \mathrm{In}$ that evaporates, indicating there is an interaction between the two elements when dilute amounts are present on the surface. When the As/In flux ratio is increased beyond 1.02, there is an additional accumulation of $\mathrm{Bi}$ on the surface that initiates the formation of droplets.

The incident and excess flux ratios and mole fractions of As and $\mathrm{Bi}$ at the droplet-free and small droplet boundaries of the As-lean and As-rich growth regimes are summarized in Table III. From the point of view of the competition of $\mathrm{Bi}$ with As for group-V sites, it is expected that reducing the As/In flux ratio would enable further incorporation of $\mathrm{Bi}$. However, as the As/In flux ratio is reduced, there is an unexpected reduction in $\mathrm{Bi}$ incorporation and the onset of $\mathrm{Bi}$ droplet formation as the excess $\mathrm{Bi}$ coalesces on the surface during As-lean growth, indicating that the interaction between $\mathrm{Bi}$ and $\mathrm{As}$ also plays a significant role in the incorporation of $\mathrm{Bi}$. For example, the droplet-free boundary for As-lean growth occurs where the As mole fraction is 0.942 $\left(\mathrm{InAs}_{0.942} \mathrm{Bi}_{0.058}\right)$ grown at $280{ }^{\circ} \mathrm{C}$ with $\mathrm{As} / \mathrm{In}=0.97$ and $\mathrm{Bi} / \mathrm{In}=0.065$, and $0.945\left(\operatorname{InAs}_{0.945} \mathrm{Bi}_{0.055}\right)$ grown at $270{ }^{\circ} \mathrm{C}$ with $\mathrm{As} / \mathrm{In}=0.99$ and $\mathrm{Bi} / \mathrm{In}=0.065$. These growth conditions result in excess fluxes of $\mathrm{As} / \mathrm{In}$ of 0.028 and $\mathrm{Bi} / \mathrm{In}$ of 0.007 at $280{ }^{\circ} \mathrm{C}$, and $\mathrm{As} / \mathrm{In}$ of 0.045 and $\mathrm{Bi} / \mathrm{In}$ of 0.010 at $270{ }^{\circ} \mathrm{C}$ (see Table III and Fig. 6). In terms of the excess group- $\mathrm{V}$ fluxes impinging on the growth surface, the excess $\mathrm{As} / \mathrm{Bi}$ flux ratio for the formation of small Bi-droplets is $\leq 4.0$ at $280{ }^{\circ} \mathrm{C}$ and $\leq 4.5$ at $270^{\circ} \mathrm{C}$. Likewise, the excess $\mathrm{As} / \mathrm{Bi}$ flux ratio in the As-rich growth regime is $\geq 7.2$ at $280^{\circ} \mathrm{C}$ and $\geq 5.6$ at $270{ }^{\circ} \mathrm{C}$; similar values are observed at the small droplet boundary (see Table III).

These results indicate that the incorporation of $\mathrm{Bi}$ is strongly affected by its interaction with As on the growth surface, where an optimal amount of As results in the maximum amount of $\mathrm{Bi}$ incorporation without the formation of Bi droplets. The presence of too little or too much As reduces the incorporation of $\mathrm{Bi}$. It seems that under the appropriate concentration, As on the growth surface behaves like a reactive surfactant enhancing the incorporation of $\mathrm{Bi}$ during the growth of InAsBi, much like Te does for In during the growth of InGaAs (Refs. 11 and 13) or the growth of 
TABLE III. Incident and excess flux ratios and mole fractions of $\mathrm{As}$ and $\mathrm{Bi}$ at the boundaries of droplet-free InAsBi growth and small Bi-droplet formation shown in Fig. 6.

\begin{tabular}{|c|c|c|c|c|c|c|c|c|c|}
\hline & & $\begin{array}{c}\text { Growth } \\
\text { temperature }\left({ }^{\circ} \mathrm{C}\right)\end{array}$ & $\begin{array}{c}\text { As/In } \\
\text { flux ratio }\end{array}$ & $\begin{array}{l}\mathrm{Bi} / \mathrm{In} \text { flux } \\
\text { ratio }\end{array}$ & $\begin{array}{l}\text { As mole } \\
\text { fraction }\end{array}$ & $\begin{array}{l}\text { Bi mole } \\
\text { fraction }\end{array}$ & $\begin{array}{l}\text { Excess } \\
\text { As/In }\end{array}$ & Excess Bi/In & Excess As/Bi \\
\hline \multirow{5}{*}{ Droplet-free boundary } & \multirow[t]{2}{*}{ As-lean growth $(\mathrm{As} / \mathrm{In}<1)$} & 280 & 0.970 & 0.065 & 0.942 & 0.058 & 0.028 & 0.007 & 4.0 \\
\hline & & 270 & 0.990 & 0.065 & 0.945 & 0.055 & 0.045 & 0.010 & 4.5 \\
\hline & \multirow[t]{2}{*}{ As-rich growth $(\mathrm{As} / \mathrm{In}>1)$} & 280 & 1.030 & 0.060 & 0.951 & 0.049 & 0.079 & 0.011 & 7.2 \\
\hline & & 270 & 1.021 & 0.065 & 0.948 & 0.052 & 0.073 & 0.013 & 5.6 \\
\hline & As-lean growth $(\mathrm{As} / \mathrm{In}<1)$ & 280 & 0.968 & 0.065 & 0.943 & 0.057 & 0.025 & 0.008 & 3.1 \\
\hline \multirow{3}{*}{ Small droplet boundary } & \multirow{3}{*}{ As-rich growth (As/In >1) } & 270 & 0.983 & 0.065 & 0.948 & 0.052 & 0.035 & 0.013 & 2.7 \\
\hline & & 280 & 1.035 & 0.060 & 0.952 & 0.048 & 0.083 & 0.012 & 6.9 \\
\hline & & 270 & 1.038 & 0.065 & 0.950 & 0.050 & 0.087 & 0.015 & 5.9 \\
\hline
\end{tabular}

binaries such as GaAs. ${ }^{11,18}$ When the As flux is decreased below a critical level, excess $\mathrm{Bi}$ on the surface coalesces forming droplets as less $\mathrm{Bi}$ is incorporated into the growing InAsBi film via the As-Bi interaction. Likewise, when the As-flux is increased above a critical level, excess $\mathrm{Bi}$ on the surface coalesces forming droplets as less $\mathrm{Bi}$ is incorporated into the growing InAsBi film via the As-Bi interaction. In the former case, there is not sufficient As on the surface to react with all of the $\mathrm{Bi}$ and in the latter case the interaction of As with itself overwhelms its interaction with Bi.

\section{OPTICAL PROPERTIES OF InAsBi}

The optical properties of several InAsBi bulk and quantum well samples are investigated using PL. The InAsBi quantum wells (listed in Table II) contain carrier confinement barriers that greatly reduce the loss of photogenerated carriers outside of the active region, and exhibit luminescence from low to room temperature. In contrast, the bulk

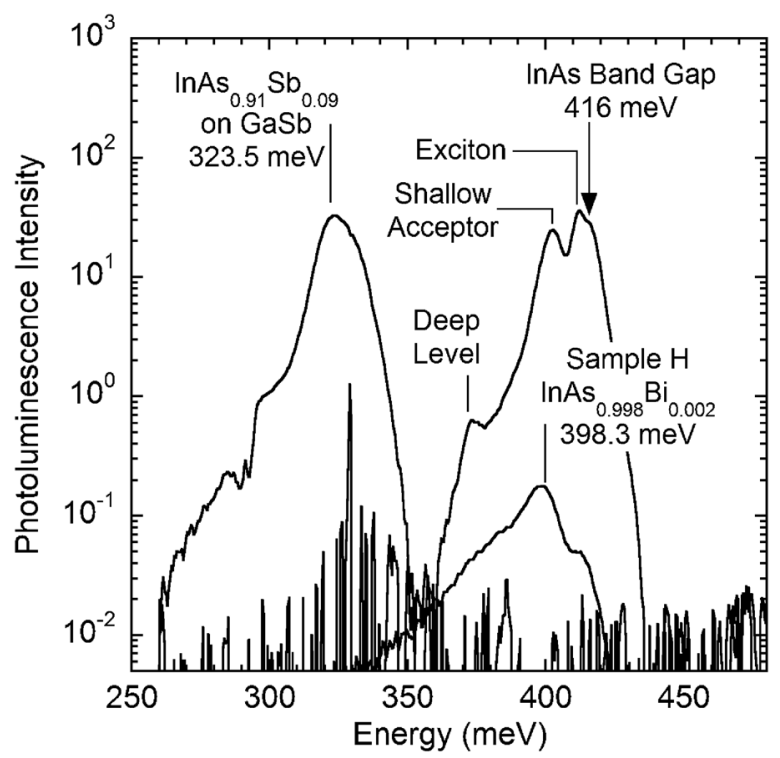

FIG. 7. Low temperature $(12 \mathrm{~K})$ photoluminescence intensity as a function of photon energy for a $300 \mu \mathrm{m}$ thick InAs substrate, a $90 \%$ relaxed $1 \mu \mathrm{m}$ thick $\mathrm{InAs}_{0.9978} \mathrm{Bi}_{0.0022}$ layer on GaSb (sample $\mathrm{H}$ ), and a $1 \mu \mathrm{m}$ thick lattice-matched $\mathrm{InAs}_{0.91} \mathrm{Sb}_{0.09}$ layer on $\mathrm{GaSb}$. Low Bi incorporation in the InAsBi layer resulted in its relaxation and the formation of Bi surface droplets, both of which act to reduce the photoluminescence intensity.
InAsBi structures do not contain carrier confinement barriers and do not exhibit luminescence for the most part due to weak confinement of photogenerated carriers. Nevertheless, low temperature luminescence is observed from sample $\mathrm{H}$ with $0.22 \% \mathrm{Bi}$. The PL spectra from sample $\mathrm{H}$, a $300 \mu \mathrm{m}$ thick InAs substrate, and a $1 \mu \mathrm{m}$ thick lattice-matched $\mathrm{InAs}_{0.91} \mathrm{Sb}_{0.09}$ layer confined by $10 \mathrm{~nm}$ AlSb layers on $\mathrm{GaSb}$ are compared in Fig. 7. These results indicate that a small amount of $\mathrm{Bi}$ provides a large reduction in the bandgap of InAs and that the rate of reduction is much greater than for $\mathrm{Sb}$.

The temperature-dependent PL from InAsBi quantum well samples 1 and 2 grown at $300{ }^{\circ} \mathrm{C}$ with a $0.021 \mathrm{Bi} / \mathrm{In}$ flux ratio is compared to a reference structure (sample 3) grown under identical conditions without Bi (see Fig. 8). In all samples, the tensile InAs layers and compressive AlSb layers are coherently strained. As a result of $\mathrm{Bi}$ incorporation, the PL peak energy of the two quantum well samples is $\sim 9 \mathrm{meV}$ below the PL peak energy of the tensilely strained InAs reference (sample 3). Band anticrossing model calculations indicate that the $\mathrm{Bi}$ mole fraction is roughly $0.15 \%$ at the center of these wafers. The variation in the temperature dependence of the bandgap of these two samples grown under nearly identical conditions is likely due to the unique bandgap reduction mechanisms of $\mathrm{Bi}$. In addition to moving the valence band up toward the conduction band, Bi clusters may form which introduce distributions of states near the valence band edge which also give photoluminescence. ${ }^{6,7}$ The temperature dependence of the PL peak energy of each sample is fit to an Einstein single oscillator model for temperatures up to $120 \mathrm{~K}$; the respective Einstein temperatures for the reference structure and quantum wells 1 and 2 are 74, 162 , and $151 \mathrm{~K}$.

The two quantum well samples are grown with slightly different As/In fluxes such that the two samples have overlapping growth conditions at different parts of the wafer. Quantum well sample 1 is grown with a 1.00-1.04 (center to edge) As/In flux ratio. Quantum well sample 2 is grown with a 0.97-1.01 (center to edge) As/In flux ratio. The peak energy and integrated intensity of the $12 \mathrm{~K} \mathrm{PL}$ is measured radially across each $50 \mathrm{~mm}$ substrate and is shown along with the As/In flux ratio in Fig. 9. The small variation in the As/In flux ratio is found to significantly affect the incorporation of $\mathrm{Bi}$ in 


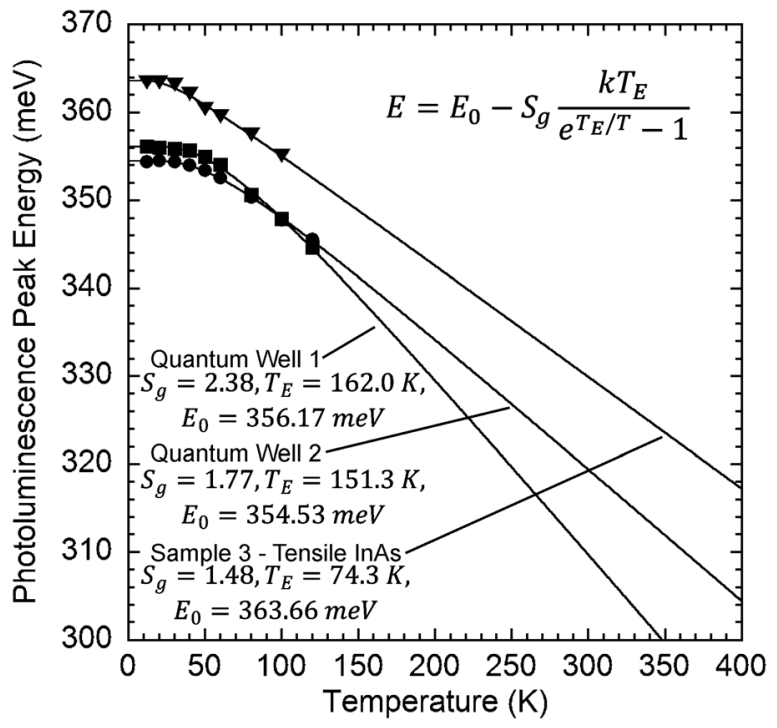

FIG. 8. Photoluminescence peak position (energy) as a function of temperature measured at the center of the wafer for two $10 \mathrm{~nm}$ thick $\operatorname{InAs} \mathrm{As}_{0.998} \mathrm{Bi}_{0.002}$ quantum wells (samples 1 and 2) and a $110 \mathrm{~nm}$ thick tensilely strained InAs layer (sample 3), which for comparison is the equivalent structure without Bi. For each sample, the temperature dependence of the photoluminescence peak energy is fit to an Einstein single oscillator model shown in the upper right corner of the plot. The best fit values for each is shown in the lower left corner.

the InAsBi quantum wells. In both samples, the photoluminescence peak energy is roughly $356 \mathrm{meV}$ at the center and decreases to a minimum of $348 \mathrm{meV}$ at the radial locations grown with a $1.01 \mathrm{As} / \mathrm{In}$ flux ratio. Comparing these two points with sample 3, the equivalent structure grown without $\mathrm{Bi}$ that emits at $364 \mathrm{meV}$ (see Fig. 8), the Bi mole fraction nearly doubles to a peak value of $0.29 \%$ at its maximum.

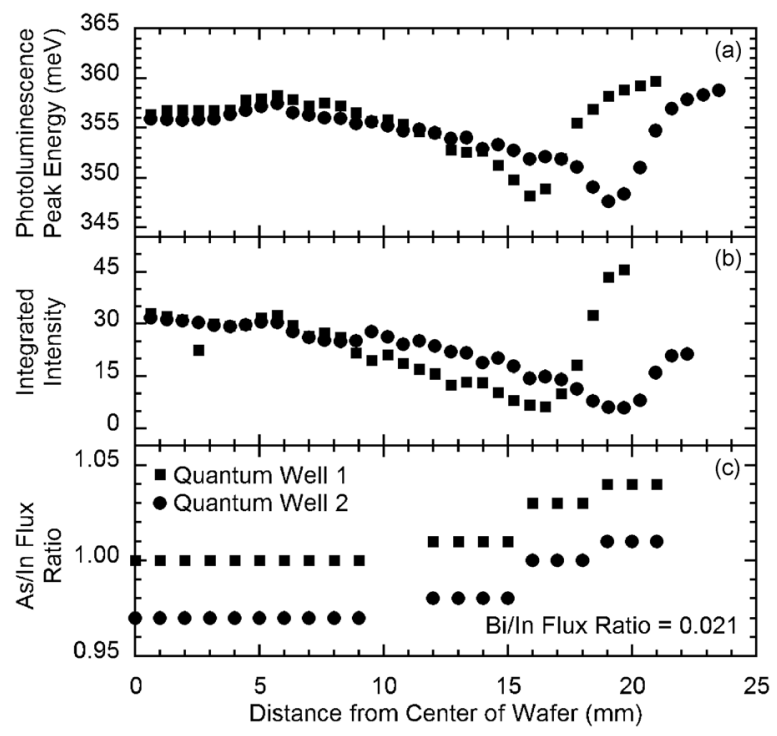

FIG. 9. Low temperature ( $12 \mathrm{~K})$ photoluminescence from two InAsBi quantum well samples grown at $300^{\circ} \mathrm{C}$ with a $\mathrm{Bi} / \mathrm{In}$ flux ratio of 0.021 , measured along the substrate radius; the peak-position energy is shown in subplot (a) and the integrated intensity in subplot (b). The radial variation in the As/In flux ratio during growth is shown in subplot (c). Both samples luminesce at $\sim 356 \mathrm{meV}(0.15 \% \mathrm{Bi}$ mole fraction) at the wafer center and the minimum photoluminescence peak-position energy of $\sim 348 \mathrm{meV}(0.29 \% \mathrm{Bi}$ mole fraction) occurs at a radial location with a $1.01 \mathrm{As} / \mathrm{In}$ flux ratio.

\section{Bi MEDIATED GROWTH OF InAs/InAsSb SUPERLATTICES}

The performance of $\mathrm{Bi}$ as a surfactant is examined during the growth of strain-balanced InAs/InAsSb superlattices at $430{ }^{\circ} \mathrm{C}$ on $\mathrm{GaSb}$ substrates. The sample structures consist of a $1 \mu \mathrm{m}$ thick 56 period superlattice with $9 \mathrm{~nm}$ of InAs and $8 \mathrm{~nm}$ of $\mathrm{InAs}_{0.81} \mathrm{Sb}_{0.19}$ between $p$ - and $n$-type GaSb layers, as shown in the inset of Fig. 11. In total, five superlattice samples are grown (listed in Table IV), four with Bi as a surfactant and one reference sample without; the Bi/In flux ratios are $0.0 \%$ (sample a), $0.3 \%$ (sample b), $1.0 \%$ (sample c), and $3.0 \%$ (samples $\mathrm{d}$ and e). The samples are characterized using RHEED, XRD, atomic force microscopy, and PL. The presence of $\mathrm{Bi}$ on the surface during growth changes the surface reconstruction of InAs from a faint $(2 \times 1)$ to a strong $(1 \times 3)$ while $\mathrm{InAsSb}$ remains unchanged with a $(2 \times 3)$ reconstruction as shown in Fig. 10. Although the presence of Bi modifies the surface reconstruction, there is no observed change in the surface morphology of the completed samples. Tapping-mode atomic force microscope measurements show that the surfaces are very smooth with a RMS roughness of $\sim 0.05 \mathrm{~nm}$ over $1 \times 1 \mu \mathrm{m}^{2}$ areas for all samples grown with and without $\mathrm{Bi}$ as surfactant.

Reciprocal space mapping shows that the superlattices are pseudomorphic; as a result, the layer thicknesses and $\mathrm{Sb}$
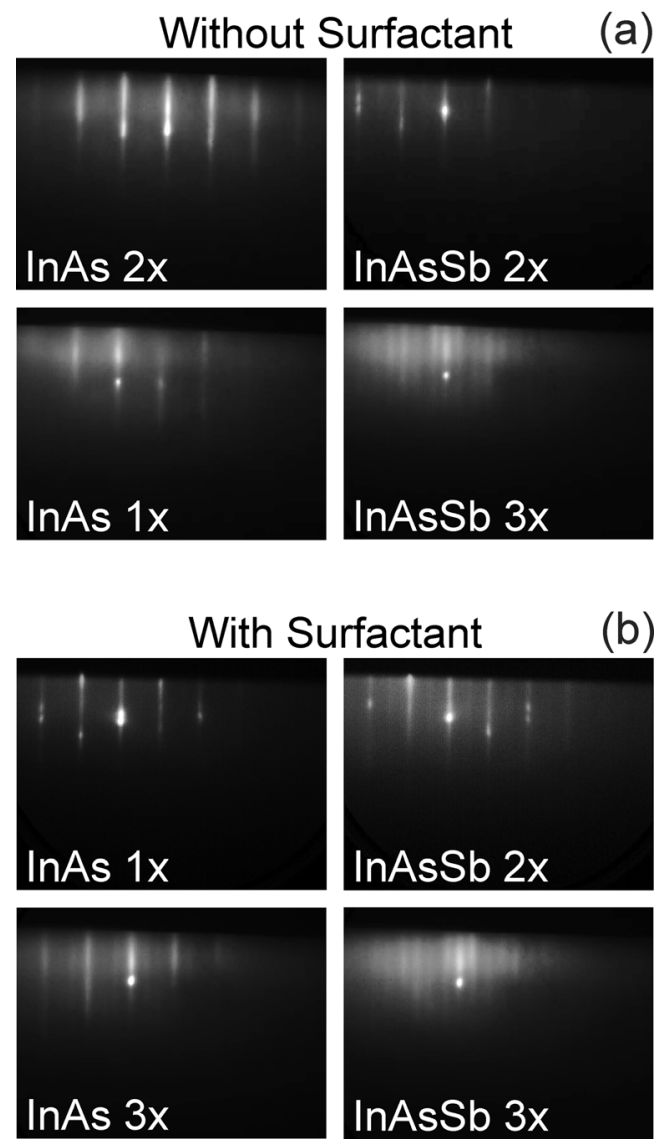

FIG. 10. Reflection high-energy electron diffraction patterns from InAs and InAsSb grown without (a) and with (b) a $\mathrm{Bi} / \mathrm{In}$ flux ratio of $3.0 \%$ as a surfactant. Bi causes the surface reconstruction of InAs to change from a weak $(2 \times 1)$ to a strong $(1 \times 3)$, while $\mathrm{InAsSb}$ remains a $(2 \times 3)$. 


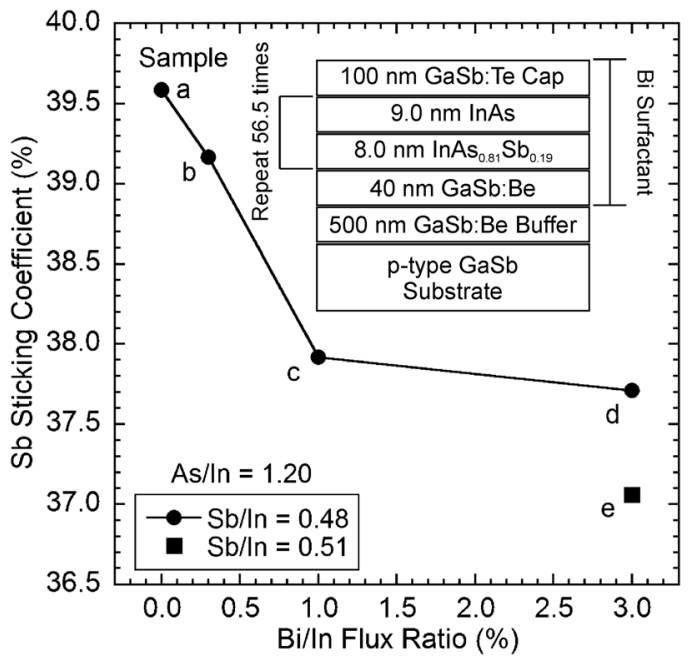

FIG. 11. Sticking coefficient of $\mathrm{Sb}$ during the $\mathrm{Bi}$ mediated growth of InAs/InAsSb superlattices (structure shown as inset) as a function of the $\mathrm{Bi} / \mathrm{In}$ flux ratio. The results from samples a-d grown with a $0.48 \mathrm{Sb} / \mathrm{In}$ flux ratio are shown by the solid circles and indicate that the presence of $\mathrm{Bi}$ on the surface reduces the Sb sticking coefficient. Sample e is grown with a $0.51 \mathrm{Sb} / \mathrm{In}$ flux ratio and a $3 \% \mathrm{Bi} / \mathrm{In}$ flux ratio (solid square), and results in similar Sb mole fraction (18.9\%) to sample a (19.0\%) achieved with 0.48 $\mathrm{Sb} / \mathrm{In}$ and no $\mathrm{Bi}$.

mole fraction are accurately acquired from 004-plane XRD measurements of each superlattice. For all samples, the layer thicknesses are identical to the target thicknesses shown in the inset of Fig. 11. Furthermore, a trend of decreasing $\mathrm{Sb}$ mole fraction in the InAsSb layers grown with a constant $\mathrm{Sb} / \mathrm{In}$ flux ratio and an increasing $\mathrm{Bi} / \mathrm{In}$ flux ratio is observed; these measurements indicate that the presence of $\mathrm{Bi}$ on the surface reduces the sticking coefficient of $\mathrm{Sb}$. The results from superlattices grown with an As/In flux ratio of 1.20, an $\mathrm{Sb} / \mathrm{In}$ flux ratio of 0.48 , and $\mathrm{Bi} / \mathrm{In}$ flux ratios of $0.0,0.3,1.0$, and $3.0 \%$ are shown as solid circles in Fig. 11. Sample a is grown without $\mathrm{Bi}$ and is perfectly strain-balanced with an $\mathrm{Sb}$ sticking coefficient of $39.6 \%$ and an $\mathrm{Sb}$ mole fraction of $19.0 \%$, while sample $\mathrm{d}$ is grown with a $\mathrm{Bi} / \mathrm{In}$ flux ratio $3.0 \%$ and is $0.03 \%$ tensilely strained with an Sb sticking coefficient of $37.7 \%$ and an $\mathrm{Sb}$ mole fraction of $18.1 \%$. The growth of sample $\mathrm{d}$ with a $\mathrm{Bi} / \mathrm{In}$ flux ratio of $3.0 \%$ is repeated using a larger $\mathrm{Sb} / \mathrm{In}$ flux ratio of 0.51 to compensate for the reduced sticking coefficient, while keeping the As/In flux ratio the same at 1.20; this sample (sample e) is near perfectly strain-balanced $(0.005 \%$ tensile strain) with an $\mathrm{Sb}$

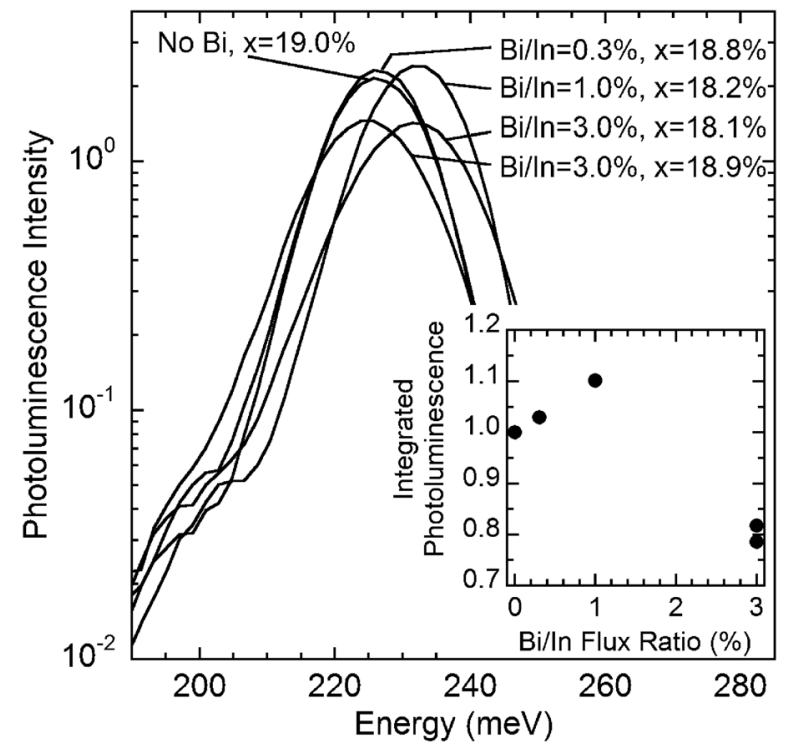

FIG. 12. Low temperature photoluminescence from InAs/InAs $\mathrm{s}_{1-\mathrm{x}} \mathrm{Sb}_{\mathrm{x}}$ strainbalanced superlattices grown with and without $\mathrm{Bi}$ as a surfactant, with integrated photoluminescence intensity shown as an inset. The $\mathrm{Bi} / \mathrm{In}$ flux ratio and the Sb mole fraction are shown for each curve. The period of each superlattice is unchanged, but the photoluminescence peak positions differ due to changes in the incorporation of $\mathrm{Sb}$, which decreases when $\mathrm{Bi}$ is present on the surface and increased when the Sb flux was increased to compensate.

sticking coefficient of $37.1 \%$ (slight decrease) and an $\mathrm{Sb}$ mole fraction of $18.9 \%$ (net increase).

The five samples grown with and without $\mathrm{Bi}$ as a surfactant exhibit low temperature PL with comparable line widths (see Fig. 12). Since the individual superlattice layers have the same thicknesses, the PL peak shifts are due to variations of the $\mathrm{Sb}$ mole fraction in the InAsSb layer. The integrated $\mathrm{PL}$ intensity is plotted as a function of $\mathrm{Bi} / \mathrm{In}$ flux ratio in the inset of Fig. 12, and shows an increase in PL with increasing $\mathrm{Bi}$-flux up to a $\mathrm{Bi} / \mathrm{In}$ flux ratio of $1.0 \%$, indicating that there is a slight improvement in the optical quality with the use of small amounts of Bi surfactant. The two samples grown with a $\mathrm{Bi} / \mathrm{In}$ flux ratio of $3.0 \%$ exhibit a reduced intensity compared to the sample grown without Bi. Under these growth conditions the optimal $\mathrm{Bi} / \mathrm{In}$ flux ratio is around $1.0 \%$. Although Bi-mediated growth did not significantly impact the surface morphology and only slightly improved the optical properties of the InAs/InAsSb superlattices in this study, it is possible that samples grown at lower temperatures with a higher $\mathrm{Sb}$ content (larger strain) may benefit further from the use of Bi as a surfactant.

TABLE IV. Growth conditions, Sb sticking coefficient, and Sb composition measured by x-ray diffraction for $1 \mu \mathrm{m}$ thick InAs/InAsSb superlattices grown on $1 / 450 \mathrm{~mm}$ GaSb substrates with and without $\mathrm{Bi}$ as a surfactant.

\begin{tabular}{|c|c|c|c|c|c|c|c|c|}
\hline Sample & $\begin{array}{l}\text { Run } \\
\text { No. }\end{array}$ & $\begin{array}{c}\text { Substrate } \\
(1 / 4 \text { or full } 50 \mathrm{~mm})\end{array}$ & $\begin{array}{l}\text { Growth temperature } \\
\qquad\left({ }^{\circ} \mathrm{C}\right)\end{array}$ & $\begin{array}{c}\mathrm{Bi} / \mathrm{In} \\
\text { flux ratio }(\%)\end{array}$ & $\begin{array}{l}\text { As/In } \\
\text { flux ratio }\end{array}$ & $\begin{array}{c}\mathrm{Sb} / \mathrm{In} \\
\text { flux ratio }\end{array}$ & $\begin{array}{l}\operatorname{InAs}_{1-x} \mathrm{Sb}_{\mathrm{x}} \\
\text { mole fraction } \mathrm{x}(\%)\end{array}$ & $\begin{array}{c}\text { Sb sticking } \\
\text { coefficient }(\%)\end{array}$ \\
\hline A & B2023 & $1 / 4$ & 430 & 0.0 & 1.20 & 0.48 & 19.0 & 39.6 \\
\hline B & B2035 & $1 / 4$ & 430 & 0.3 & 1.20 & 0.48 & 18.8 & 39.2 \\
\hline $\mathrm{C}$ & B2024 & $1 / 4$ & 430 & 1.0 & 1.20 & 0.48 & 18.2 & 37.9 \\
\hline $\mathrm{D}$ & B2026 & $1 / 4$ & 430 & 3.0 & 1.20 & 0.48 & 18.1 & 37.7 \\
\hline $\mathrm{E}$ & B2028 & $1 / 4$ & 430 & 3.0 & 1.20 & 0.51 & 18.9 & 37.1 \\
\hline
\end{tabular}




\section{CONCLUSIONS}

The substrate temperatures and group- $\mathrm{V}$ fluxes for the growth of smooth, high structural-quality, nearly latticematched InAsBi on GaSb substrates without the formation

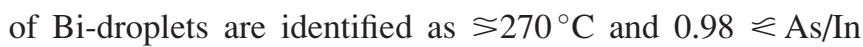
$₹ 1.02$ with $\mathrm{Bi} / \mathrm{In} \cong 0.065$. The maximum incorporation of $\mathrm{Bi}$ occurs in this growth window, where Bi compositions up to $5.8 \%$ are realized. Outside this growth window, less $\mathrm{Bi}$ incorporates and the excess $\mathrm{Bi}$ coalesces into surfacedroplets. Droplet formation occurs when the excess $\mathrm{As} / \mathrm{Bi}$ flux ratios are either $₹ 4$ or $₹ 6$, indicating that the presence of an optimal amount of As on the growth surface functions as an efficient reactive surfactant assisting the incorporation of $\mathrm{Bi}$. Likewise, the incorporation of $\mathrm{Bi}$ in $\mathrm{InAsBi} / \mathrm{InAs}$ quantum wells grown at $300^{\circ} \mathrm{C}$ is found to be sensitive to the As/In flux ratio; the maximum $0.29 \% \mathrm{Bi}$ mole fraction observed occurs at a $1.01 \mathrm{As} / \mathrm{In}$ flux ratio and a $0.021 \mathrm{Bi} / \mathrm{In}$ flux ratio. During the growth of InAs/InAsSb superlattices at $430^{\circ} \mathrm{C}, \mathrm{Bi}$ as a surfactant modifies the surface reconstruction of InAs, reduces the Sb sticking coefficient, does not significantly impact the surface morphology, and enhances the optical properties of the completed structures for $\mathrm{Bi} / \mathrm{In}$ flux ratios around $1.0 \%$.

\section{ACKNOWLEDGMENTS}

The authors gratefully acknowledge financial support through the National Science Foundation, Grant No. DMR0909028 and the U.S. Army Research Office MURI program, Grant No. W911NF-10-1-0524. The authors also acknowledge the use of facilities in the LeRoy Eyring Center for Solid State Science and the John M. Cowley Center for High Resolution Electron Microscopy at Arizona State University.

${ }^{1}$ A. Janotti, Su-Huai Wei, and S. B. Zhang, Phys. Rev. B 65, 115203 (2002).

${ }^{2}$ I. Vurgaftman, J. R. Meyer, and L. R. Ram-Mohan, J. Appl. Phys. 89, 5815 (2001).

${ }^{3}$ N. A. Riordan et al., J. Mater. Sci.: Mater. Electron. 23, 1799 (2012).

${ }^{4}$ S. Francoeur, M.-J. Seong, A. Mascarenhas, S. Tixier, M. Adamcyk, and T. Tiedje, Appl. Phys. Lett. 82, 3874 (2003).

${ }^{5}$ V. Pačebutas, K. Bertulis, L. Dapkus, G. Aleksejenko, A. Krotkus, K. M. $\mathrm{Yu}$, and W. Walukiewicz, Semicond. Sci. Technol. 22, 819 (2007).

${ }^{6}$ C. Gogineni, N. A. Riordan, S. R. Johnson, X. Lu, and T. Tiedje, Appl. Phys. Lett. 103, 041110 (2013).

${ }^{7}$ S. Imhof et al., Appl. Phys. Lett. 96, 131115 (2010).

${ }^{8}$ G. B. Stringfellow and P. E. Greene, J. Electrochem. Soc. 118, 805 (1971).

${ }^{9}$ K. Alberi et al., Phys. Rev. B 75, 045203 (2007).

${ }^{10}$ Z. M. Fang, K. Y. Ma, R. M. Cohen, and G. B. Stringfellow, J. Appl. Phys. 68, 1187 (1990).

${ }^{11}$ J. Massies and N. Grandjean, Phys. Rev. B 48, 8502 (1993).

${ }^{12}$ N. Grandjean, J. Massies, and V. H. Etgens, Phys. Rev. Lett. 69, 796 (1992).

${ }^{13}$ J. Massies, N. Grandjean, and V. H. Etgens, Appl. Phys. Lett. 61, 99 (1992).

${ }^{14}$ Yu. G. Sadofyev, S. R. Johnson, S. A. Chaparro, Y. Cao, D. Ding, J.-B. Wang, K. Franzreb, and Y.-H. Zhang, Appl. Phys. Lett. 84, 3546 (2004).

${ }^{15}$ S. R. Johnson, Yu. G. Sadofyev, D. Ding, Y. Cao, S. A. Chaparro, K. Franzreb, and Y.-H. Zhang, J. Vac. Sci. Technol. B 22, 1436 (2004).

${ }^{16}$ S. Tixier, M. Adamcyk, E. C. Young, J. H. Schmid, and T. Tiedje, J. Cryst. Growth 251, 449 (2003).

${ }^{17}$ E. C. Young, S. Tixier, and T. Tiedje, J. Cryst. Growth 279, 316 (2005).

${ }^{18}$ C. D. Consorte, C. Y. Fong, M. D. Watson, L. H. Yang, and S. Ciraci, Mater. Sci. Eng. B 96, 141 (2002). 